\title{
A new species of the plagiaulacoid multituberculate mammal Eobaatar from the Early Cretaceous of southern Britain
}

\author{
Steven C. Sweetman \\ Acta Palaeontologica Polonica 54 (3), 2009: 373-384 doi: http://dx.doi.org/10.4202/app.2008.0003
}

Until recently, the only mammal remains to be obtained from the Early Cretaceous (Barremian, Wealden Group) Wessex Formation of the Isle of Wight, southern England were a poorly preserved left $\mathrm{m} 2$ and a well preserved left 12 crown representing one or possibly two plagiaulacoid multituberculate species. These were recovered in the early 1970s but despite subsequent efforts by a number of workers to recover additional Mesozoic mammal remains none were forthcoming until comprehensive bulk screening of the Wessex Formation was undertaken in a study commenced in 2002. This study resulted in the recovery of a number of new specimens representing an assemblage of at least six taxa. Among these are a well-preserved plagiaulacoid multituberculate left $\mathrm{m} 1$ and a similarly preserved left I3. The former permits diagnosis of a new species of eobaatarid, Eobaatar clemensi sp. nov. The previously recovered left $\mathrm{m} 2$ is also tentatively assigned to the same taxon. In addition, another left $\mathrm{m} 1$, somewhat worn as a result of dietary attrition, was recently obtained by a private collector. This is of very similar morphology to the holotype of E. clemensi but slightly larger. It is undoubtedly referable to the same taxon and provides some insight into intraspecific size, and other minor morphological variations in the teeth of the new species. The I3 may also be referable to the new species, in which case it is the first well preserved $\mathrm{I} 3$ of a member of Eobaataridae to be fully described.

Key words: Mammalia, Multituberculata, Plagiaulacoidea, Wealden, Barremian, Cretaceous, England.

Steven C. Sweetman [steven.sweetman@port.ac.uk], University of Portsmouth, School of Earth and Environmental Sciences, Burnaby Building, Burnaby Road, Portsmouth, PO1 3QL, UK.

This is an open-access article distributed under the terms of the Creative Commons Attribution License (for details please see creativecommons.org), which permits unrestricted use, distribution, and reproduction in any medium, provided the original author and source are credited. 
PoF Full text (435.2 kB) 